\title{
Gastrointestinal hemorrhage and gynecomastia as first signs of metastatic testicular choriocarcinoma
}

\author{
Marianna Salemme ${ }^{1}$, Riccardo Nascimbeni ${ }^{2}$, Andrea Tironi ${ }^{1}$, Regina Tardanico ${ }^{1}$, Giampaolo \\ Cengia $^{3}$, Claudio Simeone ${ }^{4}$, Piero Foccoli ${ }^{5}$, Gabrio Bassotti ${ }^{6}$, Vincenzo Villanacci ${ }^{1}$ \\ 1. Department of Pathology, Spedali Civili Brescia, Italy. 2. Department of Surgery, Spedali Civili Brescia, Italy. 3. \\ Digestive Surgical Endoscopy, Spedali Civili Brescia, Italy. 4. Department of Urology, Spedali Civili Brescia, Italy. 5. \\ Department of Respiratory Endoscopy and Laser Therapy, Spedali Civili Brescia, I taly. 6. Gastroenterology and Hepatology \\ Section, Department of Medicine, University of Perugia, Perugia, Italy
}

Correspondence: Vincenzo Villanacci. Address: Department of Pathology, Spedali Civili Brescia, 25123 Brescia, Italy. Email: villanacci@spedalicivili.brescia.it

Received: February 6, 2014

DOI : $10.5430 /$ crim.v1n2p92
Accepted: February 23, $2014 \quad$ Online Published: April 11, 2014

URL: http://dx.doi.org/10.5430/crim.v1n2p92

\section{Abstract}

Testicular choriocarcinoma is an infrequent non seminomatous germ cell tumor, usually presenting histologically as part of a mixed germ cell tumor, and rarely as pure form. It metastasizes early, usually along hematogenous routes, lungs being the most frequent sites of metastasis. Involvement of the gastro-intestinal tract as metastatic site is extremely uncommon and rarely described in the literature. We report the case of a 47 year-old male with gastric and pulmonary metastases from testicular mixed germ cell tumor mainly represented by choriocarcinoma as histological subtype, presenting with melena and gynecomastia as first clinical signs. Morphological and immunohistochemical analyses of biopsies taken from the endoscopically identified gastric hemorrhagic lesion and from lung nodules showed undifferentiated neoplastic epithelial cells in a necrotic and hemorrhagic background. Coexistence of gynecomastia addressed towards an hormonal-dependent tumor and prompted us to apply further morphological and immunohistochemical analyses, revealing the gonadal primary neoplasm, subsequently confirmed at surgery.

\section{Keywords}

Testicular choriocarcinoma, Gastrointestinal metastasis, Gynecomastia, Human chorionic gonadotropins, Syncytiotrophoblastic cells

\section{I ntroduction}

Testicular choriocarcinomas are the rarest non seminomatous germ cell tumors, with an incidence of about 0.8 cases per year per 100000 male population in those countries with the highest frequency of testicular cancer ${ }^{[1,2]}$, and display a peak incidence between 25 and 30 years ${ }^{[1]}$ and an aggressive biological behavior. Patients typically have high levels (commonly greater than $100,000 \mathrm{mIU} / \mathrm{ml}$ ) of circulating human chorionic gonadotropin $\beta$ subunit ( $\beta \mathrm{hCG}$ ); this biochemical marker is also useful as a prognostic indicator, since persistence of elevated $\beta \mathrm{hCG}$ means residual tumor and worse prognosis ${ }^{[2]}$. Because of the cross-reactivity of $\beta$ hCG with luteinizing hormone, Leydig cell hyperplasia causes gynecomastia in about $10 \%$ patients ${ }^{[2]}$. In most cases the primary lesion is usually of minute size, clinically undetected, 
while early hematogenous spread frequently produces widespread hemorrhagic metastases as the first clinical manifestation ${ }^{[3]}$. Approximately $70 \%$ of patients have metastatic disease at the time of diagnosis, and a worse prognosis than other forms of testicular germ cell tumors ${ }^{[2]}$. The lungs are the most frequent sites of metastasis ${ }^{[4]}$; other frequent metastatic sites are retroperitoneal lymph nodes ${ }^{[3,5]}$, brain, bones and liver ${ }^{[5]}$. Metastasis to gastrointestinal tract is an extremely rare event, reported in less than $5 \%$ of cases ${ }^{[6]}$, with the stomach as the most common location ${ }^{[7]}$; usually the lesion appears as a polypoid mass with central ulceration and active bleeding ${ }^{[8]}$. Standard treatment of choriocarcinoma includes orchiectomy and cyclical chemotherapy ${ }^{[9]}$, that yields a high remission rate and a 5-year survival rate of $70 \%-80 \%$ for metastatic choriocarcinoma; however, the occurrence of gastrointestinal hemorrhage worsen the prognosis ${ }^{[5]}$.

We describe a case of gastric and pulmonary metastasis from testicular mixed germ cell tumor in which the first clinical manifestations were gastrointestinal hemorrhage and gynecomastia.

\section{Case report}

A 47-year-old male with no significant previous medical history presented with one week melena without other signs or symptoms. Upper gastrointestinal endoscopy revealed a polypoid lesion on the anterior wall of the gastric body, $1 \mathrm{~cm}$ diameter, with ulcerated mucosa and active bleeding. Biopsies were obtained from the lesion and the bleeding controlled by endoscopic clipping. A diagnosis of "poorly-differentiated carcinoma" was reported. Chest and abdominal CT scans revealed five bilateral hypodense pulmonary lesions and three pelvic bone lesions. Transthoracic fine needle aspiration was attempted, but no diagnostic material was obtained. A transbronchial biopsy was performed. A second endoscopy after a few days confirmed the gastric polypoid lesion with necrotic and friable surface without active bleeding; multiple biopsies were again obtained. The patient concurrently developed gynecomastia. The hypothesis of an hormonedependent neoplasm was considered and after morphological and immunohistochemical analyses (see below) the diagnosis of gastric and pulmonary metastasis from testicular choriocarcinoma was made. Serum levels of chorionic gonadotropins were $319000 \mathrm{mUI} / \mathrm{ml}$ (reference range, $0-5 \mathrm{mUI} / \mathrm{ml}$ ). A testicular ultrasound showed a $1.5 \mathrm{~cm}$ diameter lesion in the left testicle; this was surgically removed. The diagnosis was mixed germ cell tumor mainly represented by choriocarcinoma as histological subtype. Treatment with cysplatin-based chemotherapy was started; serum levels of chorionic gonadotropins decreased from 500000 to $150000 \mathrm{mUI} / \mathrm{ml}$ after the first cycle and after the fourth cycle went down to $26 \mathrm{mUI} / \mathrm{ml}$.

\section{Materials and methods}

Gastric and pulmonary lesions. Biopsies were fixed in formalin and embedded in paraffin for morphological evaluation. Four micron tissue sections were stained for the following antigens: epithelial membrane antigen - EMA (Novocastra Laboratories, Newcastle upon Tyne, UK), striated muscle actin - SMA (Novocastra), CD117 (Dako, Glostrup, Denmark), cytokeratin 7 (Dako), carcinoembryonic antigen - CEA (Novocastra), vimentin (Novocastra), S-100 protein (Novocastra) and chorionic beta-gonadotrophin - $\beta$-hCG (Dako). Four micron tissue sections obtained from transbronchial biopsy were stained for the following antigens: cytokeratin 7 (Dako) and chorionic beta-gonadotrophin - $\beta$-hCG (Dako).

Testicular lesion. A $5 \mathrm{~cm} \times 3.6 \mathrm{~cm} \times 2 \mathrm{~cm}$ left testicle was surgically removed. It was fixed in formalin and embedded in paraffin for morphological and immunohistochemical analyses. Four micron tissue sections were stained for the following antigens: cytokeratin 7 (Dako), chorionic beta-gonadotrophin - $\beta$-hCG (Dako), CD30 (Dako). 


\section{Results}

Gastric and pulmonary lesions. Most samples obtained from the first upper gastrointestinal endoscopy were extremely necrotic; however, neoplastic cellular proliferation mainly composed of poorly-differentiated epithelial cells, arranged in solid nests was detectable in one biopsy. Unfortunately, the paucity of histological material did not allow to perform immunohistochemistry and a diagnosis of "poorly-differentiated carcinoma" was made (see Figure 1). Several fragments of gastric mucosa obtained from the second endoscopy also resulted completely necrotic; in two fragments it was recognizable an atypical cellular proliferation composed of multinucleated cells with eosinophilic cytoplasm and hyperchromatic nuclei, intermingled with smaller atypical cells with pale cytoplasm and a single, irregular nucleus. At immunohistochemistry both types of atypical cells resulted negative for most markers (EMA, SMA, CD117, CEA, Vimentin, and S-100 protein), and strongly positive for cytokeratin 7. Samples obtained from transbronchial biopsy showed an extensively necrotic and hemorrhagic background with a few atypical pleomorphic cells; cytokeratin 7 revealed diffuse positivity. Further immunohistochemical investigation for $\beta$-hCG revealed diffuse positivity in atypical cells on both gastric and pulmonary biopsies (see Figure 2).

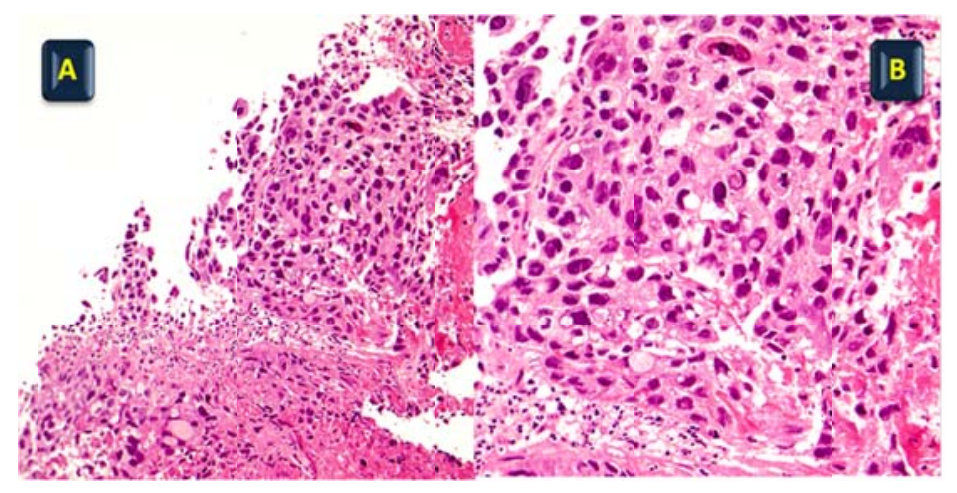

Figure 1. Biopsy specimens obtained from the first upper gastrointestinal endoscopy revealed neoplastic cellular proliferation arranged in solid nests $(\mathrm{H} \& \mathrm{E}$; A: original magnification $\times 20$, B: original magnification $\times 40$ ).

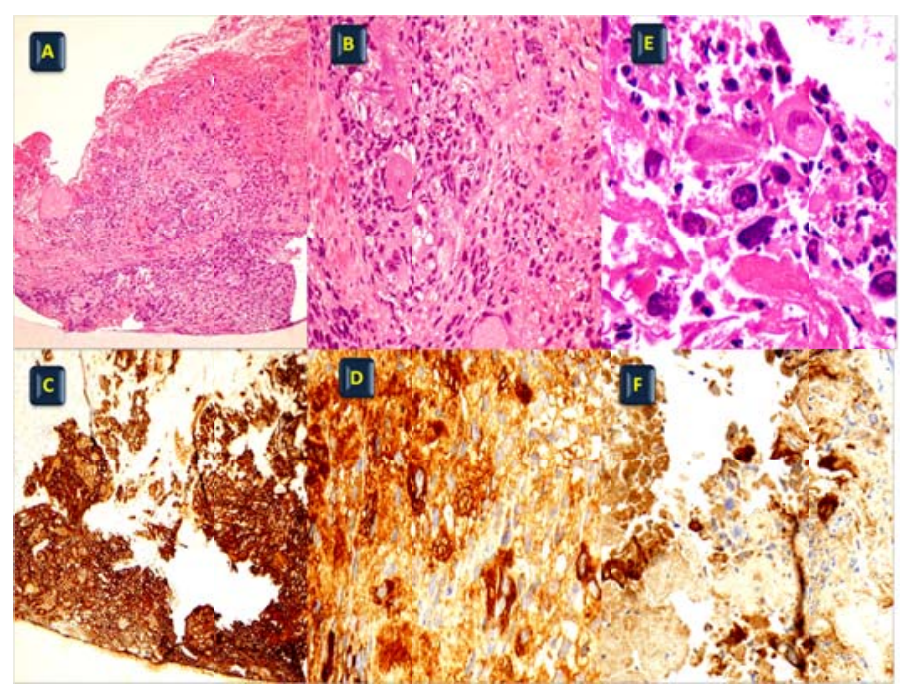

Figure 2. Biopsies obtained from the second upper endoscopy (H\&E; A: original magnification $\times 20$, B: original magnification $\times 40)$. Neoplastic cells resulted strongly positive for $\beta$-HCG $(\mathrm{C}$ : original magnification $\times 20)$ and cytokeratin 7 (D: original magnification $\times 40$ ). Transbronchial biopsy of pulmonary lesions revealed scattered neoplastic cells $(\mathrm{H} \& \mathrm{E}$; E: original magnification $\times 40)$ strongly positive for $\beta$-HCG $(\mathrm{F}$ : original magnification $\times 40)$. 
Testicular lesion. Gross examination revealed a $1.5 \mathrm{~cm} \times 1.5 \mathrm{~cm}$ well circumscribed nodular, solid, hemorrhagic lesion with irregular margins. Histopathological examination revealed the presence of a neoplastic proliferation composed of different cell types in a remarkably necrotic-hemorrhagic background. About $70 \%$ of the lesion was constituted by multinucleated cells with eosinophilic cytoplasm and several, large, hyperchromatic nuclei, intermingled with cells displaying clear cytoplasm with a single, irregular nucleus and prominent nucleolus. The former reacted strongly with $\beta$ hCG antibodies, while both cell types resulted positive for cytokeratin 7 (see Figure 3). In addition, other histological subtypes were present: mature teratoma (20\% of the lesion), seminoma (5\%) and embryonal carcinoma (5\%). It was detected intratubular germ cell neoplasia (ITGCN). No tumor was found in tunica albuginea, rete testis, epididymis and spermatic cord; vascular invasion was present.

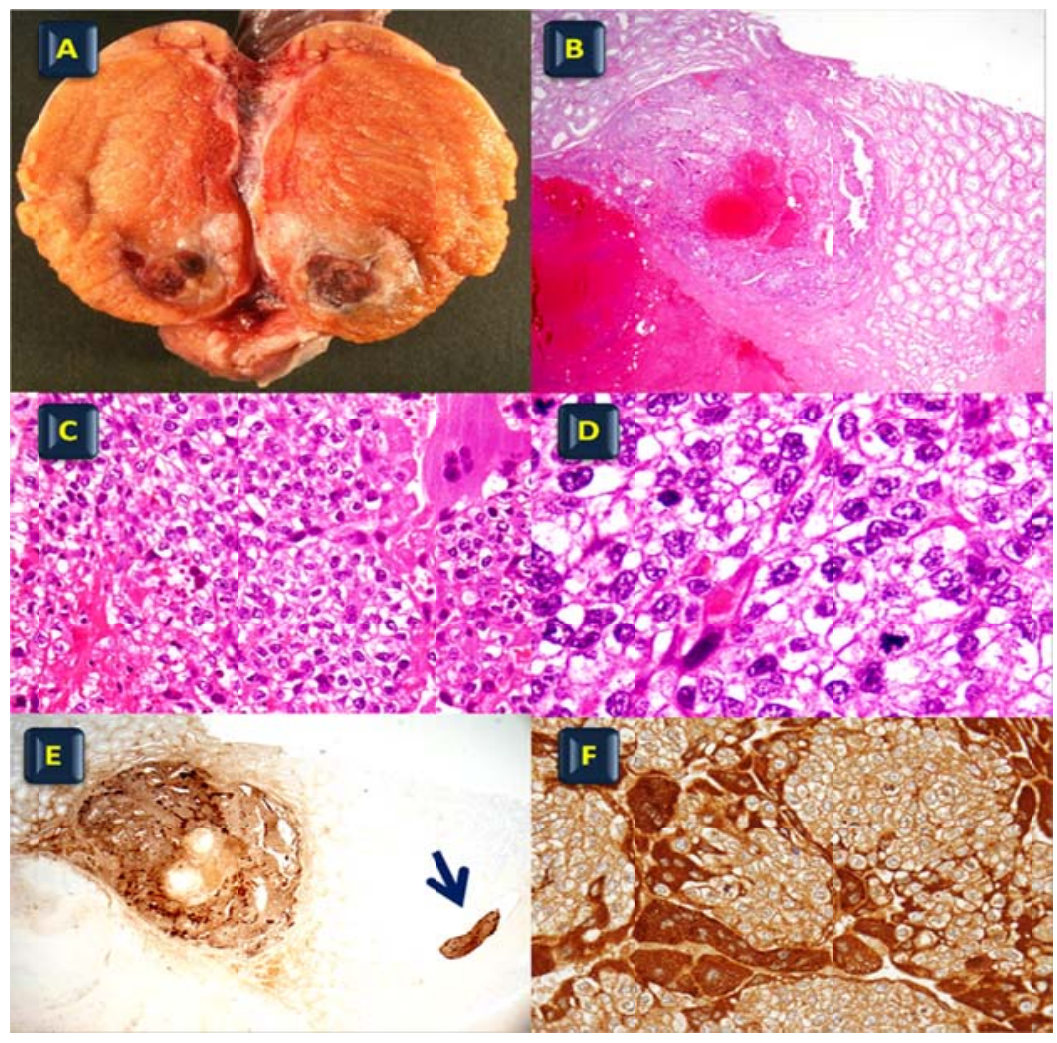

Figure 3. Gross examination of left testicle revealed a $1.5 \mathrm{~cm} \times 1.5 \mathrm{~cm}$ nodular, solid, hemorrhagic lesion with irregular margins (A). Histologically it was detectable a neoplastic proliferation mostly composed of a biphasic population: multinucleated cells with eosinophilic cytoplasm and several, large, hyperchromatic nuclei intermingled with cells having clear cytoplasm with a single, irregular nucleus and prominent nucleolus $(\mathrm{H} \& \mathrm{E}$; B: original magnification $\times 10$; C: original magnification $\times 20$; D: original magnification $\times 40$ ); the former cells strongly reacted with $\beta$ hCG antibodies (E: original magnification $\times 10$; F: original magnification $\times 40$ ). The arrow shows vascular invasion.

\section{Discussion}

We report a case of metastatic testicular mixed germ cell tumor mainly represented by choriocarcinoma as histological subtype, presenting with gastrointestinal hemorrhage and gynecomastia as unique clinical manifestations, in the absence of prior significant medical history. Testicular choriocarcinomas are the rarest non seminomatous germ cell tumors; pure testicular choriocarcinoma represents less than $1 \%$ of testicular tumors, and it is mixed with other germ cell tumor elements in $8 \%$ of testicular germ cell tumors ${ }^{[2]}$. It is characterized by rapid proliferation, excessive vascularity due to its trophoblastic origin and a tendency to outgrow its blood supply, with subsequent necrosis of the tumor ${ }^{[10]}$. As in our case, 
the primary lesion is typically small and well circumscribed from the remaining testicular parenchyma, clinically undetected ${ }^{[3]}$, while the first clinical manifestations are due to metastases. Indeed, approximately $70 \%$ patients display metastatic disease at the time of diagnosis, giving to this neoplasm a worse prognosis than most other testicular germ cell tumours ${ }^{[2]}$; moreover, older autopsy series reported approximately the same high percentage of gastrointestinal tract involvement ${ }^{[11]}$.

Haemorrhage in multiple visceral sites represents one of the hallmarks of the so-called "choriocarcinoma syndrome" ${ }^{[12]}$, characterized by haemoptysis, dyspnoea, central nervous system dysfunction, haematemesis, melena, hypotension, and anaemia ${ }^{[2]}$. Macroscopically, the tumor often presents as a small, usually hemorrhagic and partially necrotic lesion sometimes surrounded by a rim of whitish preserved tumor tissue ${ }^{[1]}$. Histologically, as in our case, there is often a mixture of different histotypes, among which choriocarcinoma represents the major component. The tumor is composed of three types of cells: syncytiotrophoblastic, cytotrophoblastic and intermediate trophoblastic cells, arranged in varying proportions and patterns in an extensively haemorrhagic and necrotic background ${ }^{[2]}$. Cytotrophoblastic cells react with cytokeratin antibodies (CK7, 8, 18, 19, CAM5.2, AE1: AE3) as well as with human placental lactogen, while syncytiotrophoblastic cells react strongly with $\beta$-hCG antibodies and also express cytokeratin, epithelial membrane antigen (EMA) and the alpha subunit of inhibin. The intermediate trophoblastic cells are positive for human placental lactogen.

The diagnosis of choriocarcinoma is based on the identification of both trophoblast types (syncytiotrophoblastic and cytotrophoblastic cells), arranged in a typically biphasic pattern ${ }^{[1]}$, because cells with the morphologic appearance of syncytiotrophoblast can be seen in several other types of testicular tumor.

Table 1. Cases of gastrointestinal involvement from metastatic testicular choriocarcinoma, either as pure form or as main part of mixed germ cell tumor hitherto reported in the literature.

\begin{tabular}{|c|c|c|c|c|c|}
\hline Reference & $\begin{array}{l}\text { Patient's } \\
\text { age (years) }\end{array}$ & Clinical manifestation & $\begin{array}{l}\text { Sites of } \\
\text { gastrointestinal } \\
\text { involvement }\end{array}$ & Testicular Histology & Outcome \\
\hline Infante et al. ${ }^{7}$ & 37 & Melena & $\begin{array}{l}\text { Stomach } \\
\text { Bowel }\end{array}$ & Pure choriocarcinoma & Dead \\
\hline Shariat et al. ${ }^{10}$ & 51 & Severe anemia, melena & $\begin{array}{l}\text { Duodenum } \\
\text { Jejunum } \\
\text { Stomach } \\
\text { Bowel }\end{array}$ & Mixed germ cell tumor & Dead \\
\hline Fosado-Gayosso et al. ${ }^{13}$ & 25 & Severe anemia, melena & Stomach & Pure choriocarcinoma & Dead \\
\hline Drake at al..$^{5}$ & 21 & Hematemesis & Stomach & Pure choriocarcinoma & $\begin{array}{l}\text { Under } \\
\text { therapy }\end{array}$ \\
\hline Lock $^{3}$ & 29 & Hematemesis, melena & Jejunum & Mixed germ cell tumor & Dead \\
\hline Stokes et al. ${ }^{14}$ & 22 & $\begin{array}{l}\text { Severe anemia, } \\
\text { hemoccult-positive } \\
\text { brown stool }\end{array}$ & Stomach & Pure choriocarcinoma & Dead \\
\hline Harikumar et al. ${ }^{15}$ & 28 & Heamatemesis & Stomach & Mixed germ cell tumor & Dead \\
\hline Saito et al. ${ }^{16}$ & 39 & Hematemesis & Stomach & Pure choriocarcinoma & Dead \\
\hline Rosenblatt et al. ${ }^{17}$ & 28 & Severe anemia, melena & Duodenum & Mixed germ cell tumor & $\begin{array}{l}\text { Not } \\
\text { specified }\end{array}$ \\
\hline
\end{tabular}

Metastasis to gastrointestinal tract is an extremely rare event, reported in less than $5 \%$ of cases ${ }^{[6]}$. In table 1 we reported cases of metastatic testicular choriocarcinoma, either as pure form or as main part of mixed germ cell tumor, with gastrointestinal involvement hitherto described in the literature ${ }^{[13-17]}$. In such cases, the stomach, usually the upper body, is the most common location ${ }^{[7]}$. Other less frequently involved sites are the small bowel (in particular the duodenum), the 
esophagus, and the colon. Neoplastic cells typically invade the submucosa and as the rapidly expanding tumor mass grows it quickly exceeds its blood supply, causing ulcerations. The main endoscopic appearance of this lesion is as a polypoid mass with central ulceration and active bleeding ${ }^{[8]}$; the latter is usually treated endoscopically by ligation, electrocautering or injective therapy (epinephrine or hjaluronate acid) ${ }^{[5]}$. However, more aggressive biopsy techniques are often necessary to obtain proper histological material. Metastatic lesions produce $\beta-\mathrm{hCG}$ and in over $90 \%$ of cases, as in our patient, the histology is identical to that of the primary tumor.

Primary extragonadal choriocarcinoma, although very rare, has been reported in medical literature, including in lung and stomach ${ }^{[18-20]}$, as well as sporadic cases of gastrointestinal hemorrhage as the first manifestation of metastatic extragonadal choriocarcinomas ${ }^{[21]}$. Non germ cells carcinomas secreting $\beta$-hCG have also been described, mainly pulmonary large cells carcinoma and pleomorphic carcinoma with giant cells component, and gynecomastia can be a paraneoplastic sign. These points must be taken into account in every case of carcinoma with choriocarcinoma-like features in patients with unknown primary neoplasm.

Recognition of a double population of atypical cells, one giant and/or multinucleated reminescent of syncytiotrophoblastic cells in a highly necrotic and hemorrhagic background should alert pathologist of the possible presence of choriocarcinoma, and to look for gonadal origin which is of course far more common for all germ cell tumors. Serological tests for $\beta$-hCG and ultrasound of genital organs should be performed in order to confirm or to rule out gonadal origin of choriocarcinoma presenting with extragonadal involvement.

The importance of clinical and serological data, that in our case addressed towards a correct diagnosis and revealed the paramount importance of a strict collaboration among different specialists, must be stressed.

\section{References}

[1] Mikuz G, Colecchia M. Tumors of the testis and paratesticular structures. In: MikuzG, ed. Clinical Pathology of urologic tumors. Informa, UK. 2007; 161-214.

[2] Eble JN, Sauter G, Epstein JI, eds Pathology and Genetics of tumours of the urinary system and male genital organs. IARC Press, Lyon; 2004.

[3] Lock MR. Testicular tumour presenting as haematemesis. Postgrad Med J. 1975; 51: 857-859. http://dx.doi.org/10.1136/pgmj.51.602.857

[4] Johnson DE, Appelt G, Samuels ML, Luna M. Metastases from testicular carcinoma. Study of 78 autopsied cases. Urology. 1976; 8: 234-239. http://dx.doi.org/10.1016/0090-4295(76)90374-5

[5] Drake MG, Nasseri J, Mills MR. Rare gastric metastasis of testicular choriocarcinoma. Gastrointest Endosc. 2007; 66: 414-416. http://dx.doi.org/10.1016/j.gie.2006.11.009

[6] Sheinfeld J. Nonseminomatous germ cell tumors of the testis: current concepts and controversies. Urology. 1994; $44: 2-14$. http://dx.doi.org/10.1016/S0090-4295(94)80002-2

[7] Molina Infante J, Beceiro Pedreño I, Ripoll Noiseux C, Marìn Jimenez I, Gonzàlez Asanza C, Menchèn Fernàndez-Pacheco P. Gastrointestinal hemorrhage due to metastatic choriocarcinoma with gastric and colonic involvement. Rev Esp Enferm Dig. 2004; 96: 77-80. http://dx.doi.org/10.4321/S1130-01082004000100010

[8] Hsu CC, Chen JJ, Changchien CS. Endoscopic features of metastatic tumors in the upper gastrointestinal tract. Endoscopy. 1996; 28: 249-253. http://dx.doi.org/10.1055/s-2007-1005437

[9] Bower M, Newlands ES, Holden L, Rustin GJ, Begent RH. Treatment of men with metastatic non-seminomatous germ cell tumours with cyclical POMB/ACE chemotherapy. Ann Oncol. 1997; 8: 477-483. http://dx.doi.org/10.1023/A:1008279222625

[10] Shariat SF, Duchene D, Kabbani W, Mucher Z, Lotan Y. Gastrointestinal hemorrhage as first manifestation of metastatic testicular tumor. Urology. 2005; 66: 1319. http://dx.doi.org/10.1016/j.urology.2005.06.102

[11] Mostofi FK. Proceedings: Testicular tumors. Epidemiologic, etiologic, and pathologic features. Cancer. 1973; 32: $1186-1201$. http://dx.doi.org/10.1002/1097-0142(197311)32:5<1186: AID-CNCR2820320527>3.0.CO;2-8 
[12] Logothetis CJ, Samuels ML, Selig DE, Ogden S, Dexeus F, Swanson D, Johnson D, von Eschenbach A. Cyclic chemotherapy with cyclophosphamide, doxorubicin, and cisplatin plus vinblastine and bleomycin in advanced germinal tumors. Results with 100 patients. Am J Med. 1986; 81: 219-228. http://dx.doi.org/10.1016/0002-9343(86)90255-X

[13] Fosado Gayosso M, Pérez Hernández JL, Bernal Sahagún F, Acevedo Garcìa C, Aquilar Ayala EL, Pérez Espinosa J. Upper gastrointestinal bleeding as an initial manifestation of metastasis, secondary to a choriocarcinoma in a patient suffering from testicular mixed cell tumour. Rev Esp Enferm Dig. 2011; 103: 46-47. http://dx.doi.org/10.4321/S1130-01082011000100013

[14] Stokes EW, Perkins C. Testicular choriocarcinoma. An unusual presentation as occult gastrointestinal blood loss. J Adolesc Health Care. 1989; 10: 146-150. http://dx.doi.org/10.1016/0197-0070(89)90106-X

[15] Harikumar R, Harish K, Aravindan KP, Thomas V. Testicular choriocarcinoma with gastric metastasis presenting as hematemesis. Indian J Gastroenterol. 2004; 23:223-224.

[16] Saito J, Miyagawa Y, Kamoto A, Yokoyama S, Kakuta Y, Mori N, Ichimaru N, Hara T, Nonomura N, Yamaguchi S, Okuyama A. Testicular cancer metastatic to multiple organs including the stomach, kidneys, and skin: a case report. Hinyokika Kiyo. 2006; 52: 297-301.

[17] Rosenblatt GS, Walsh CJ, Chung S. Metastatic testis tumor presenting as gastrointestinal hemorrhage. J Urol. 2000 ; $164: 1655$. http://dx.doi.org/10.1016/S0022-5347(05)67057-7

[18] Fraire AE, Dail DH. Germ Cell Tumors. In: Dail and Hammar's Pulmonary Pathology. Neoplastic Lung Disease. Springer, NY, 2008; 516 p.

[19] Okutur K, Hasbal B, Aydin K, Bozkurt M, Namal E, Oz B, Kaynak K, Demir G. Pleomorphic carcinoma of the lung with high serum beta human chorionic gonadotropin level and gynecomastia. J Korean Med Sci. 2010; 25: 1805-1808. http://dx.doi.org/10.3346/jkms.2010.25.12.1805

[20] Liu Z, Mira JL, Cruz-Caudillo JC. Primary gastric choriocarcinoma. A case report and review of the literature. Arch Pathol Lab Med. 20011; 25: 1601-1605.

[21] Shibuya T, Osada T, Kodani T, Hojo M, Saito H, Ueyama H, Kato J, Nagahara A, Otaka M, Ogihara T, Nagao K, Fujime M, Watanabe S. Gastrointestinal hemorrhage as the first manifestation of metastatic extragonadal choriocarcinoma. Intern Med. 2009; 48: 551-554. http://dx.doi.org/10.2169/internalmedicine.48.1867 